\title{
Specific migration of IRGASTAB 17 MOK and DBP from rigid and plasticized poly(vinyl chloride) into organic liquids
}

\author{
A. Amara ${ }^{1}$, C. Zeddam ${ }^{2}$, and N. Belhaneche-Bensemra ${ }^{2}$ \\ ${ }^{1}$ Laboratory of Chemical Engineering, Department of Industrial Chemistry, Faculty of Engineering, University Saad \\ Dahleb Blida, road Soumaa BP 270 Blida, Algeria \\ ${ }^{2}$ Laboratory of Science and Environmental Technology, Department of Environmental Engineering, National Polytechnic \\ School, PO Box 182, El-Harrach, Algeria
}

\begin{abstract}
The aim of this paper is the determination of the specific migration of a plasticizer and an organotin heat stabilizer (IRGASTAB $17 \mathrm{MOK}$ ) from plasticized and rigid PVC into organic liquids, hexane and ethanol simulating fatty food. The migration test conditions were 10 days at $40^{\circ} \mathrm{C}$ and 2 hours at $70^{\circ} \mathrm{C}$. FTIR and UVVisible at $490 \mathrm{~nm}$ spectroscopy and gas chromatography were used to investigate the migration phenomena. The influence of various parameters such as temperature time of contact and the nature of food simulant were considered. The results show that plasticizer accelerates the heat stabilizer migration. On the other hand that gas chromatography could be substituted by FTIR spectroscopy to investigate the DBP migration phenomena. It is a simple, low cost and rapid method which can be used.
\end{abstract}

\section{Introduction}

Gadgets and toys for children and babies are made of plasticized and rigid PVC. The suppleness article is due to the phthalates addition such as DBP, DEHP. To increase the heat stability of PVC, different metal soaps like $\mathrm{Pb}, \mathrm{Cd}, \mathrm{Ca}$ and $\mathrm{Zn}$ carboxylates and some di- and mono-alkyltin compounds are used $[1,2]$. In contact with liquid media (saliva, fatty foods) these additives may migrate from these items and cause toxicity problems. Indeed, phthalate plasticizers are suspected of be carcinogenic. The toxicity of organotin compounds is associed with impurities, such as the dialkyl and tetra alkyl-tin; they affect the cerebral and renal systems. Furthermore, the tin can compete with the calcium in the bone $[3,4]$.

The aim of the present paper is to carry out a kinetic study of the specific migration of an organotin heat stabilizer and DBP from rigid and plasticized PVC films into food simulants at $40{ }^{\circ} \mathrm{C}$ and $70{ }^{\circ} \mathrm{C}$ by gas chromatography, FTIR spectroscopy and UV-Visible at $490 \mathrm{~nm}$.

\section{Experimental}

\subsection{Products}

Commercial grade PVC from Sheintech, dibutyl phtalate PALATINOLAH-L (DBP), DEHP (intern standard) from Prolabo and the heat stabilizer IRGASTAB 17 MOK (dioctyl tin bis 2-ethyl hexyl thioglycolate), a yellowish liquid with $\%$ of tin: $15,3 \pm 0,5$ and $\%$ of monooctyl tin: $28,8 \% \pm 3$ from Ciba Geigy were used. The chemical structure of IRGASTAB 17 MOK and DBP are shown in Figure1. Tetrahydrofuran, ethanol and hexane were purchased from Prolabo.

\subsection{PVC films preparation and migration tests}

Rigid formulations $\mathrm{FR}_{\mathrm{x}}$ containing (x wt \%: 0.75; 1.5; $2.5 ; 3.5$ and 4.5) of IRGASTAB $17 \mathrm{MOK}$ were considered. Plasticized films contain $50 \%$ of DBP and $\mathrm{x} \%$ of IRGASTAB $17 \mathrm{MOK}$ (x wt \%: $0.75 ; 1.5 ; 2.5$; 3.5 and 4.5 ). The PVC films were prepared by dissolving completely the compounds in tetrahydrofuran. The solution was transferred into a petri dish and the solvent was evaporated at room temperature during 24 hours, then the films were dried at $50^{\circ} \mathrm{C}$ in a thermostatically controlled chamber for 2 hours. Square films $\left(2 \times 2 \mathrm{~cm}^{2}\right)$ with $120 \mu \mathrm{m}$ of thickness were cut and used. The weights of the films were $0.0540 \pm 0.0041 \mathrm{~g}$.

Migration tests were carried out by immersing 10 films and/or $\mathrm{FR}_{\mathrm{x}}$ in $100 \mathrm{~mL}$ ethanol and/or hexane. Testing conditions (time, temperature) were chosen according to EU Directives 82/711/EEC and 85/572 EEC [5]. Test temperatures and times were two weeks at $40^{\circ} \mathrm{C}$ and 2 hours at $70^{\circ} \mathrm{C}$. A square film and $10 \mathrm{ml}$ of liquid were taken off at regular intervals. Films and $\mathrm{FR}_{\mathrm{x}}$ were analyzed by using a Shimadzu FTIR 8000 PC infrared spectrophotometer with 40 scans per sample and a resolution of $2 \mathrm{~cm}^{-1}$. The $\mathrm{KBr}$ pellets were used for organotin heat stabilizer and DBP. IRsolution software was used for spectra processing data. Before analysis, the films were wiped and dried at $50^{\circ} \mathrm{C}$ in a thermostatically 
controlled chamber for 24 hours to desorb the liquid simulators. In ethanol and hexane, heat stabilizer migration was detected by the Shimadzu UV-160 spectrophotometer at $490 \mathrm{~nm}$ of the red complex by reacting the organotin and dithizone [6,7]. DBP was detected by chromatograph using Shimadzu GC 17A (Debit vector gas $\mathrm{N}_{2}: 24 \mathrm{~L} / \mathrm{min}, 80 \mathrm{kPa}$ column SE 30, T column $=250^{\circ} \mathrm{C} \mathrm{T}_{(\text {detector FID) }}=320^{\circ} \mathrm{C}, \mathrm{T}_{\text {inj }}=300^{\circ} \mathrm{C}$ ).

\section{Results and discussion}

\subsection{DBP Migration: FTIR and CPG investigation}

FTIR spectra of IRGASTAB 17 M0K, DBP, virgin PVC, $\mathrm{FR}_{\mathrm{x}}$ and films given in figure 1 show $\mathrm{C}=\mathrm{O}, \mathrm{C}-\mathrm{O}$, $\mathrm{C}-\mathrm{S}$ and $\mathrm{C}-\mathrm{Sn}$ functions vibration [8]. Interactions plastic/liquid are manifested by the double migration of $\mathrm{PVC}$ additives to liquid and liquid in the polymer matrix $[9,10]$
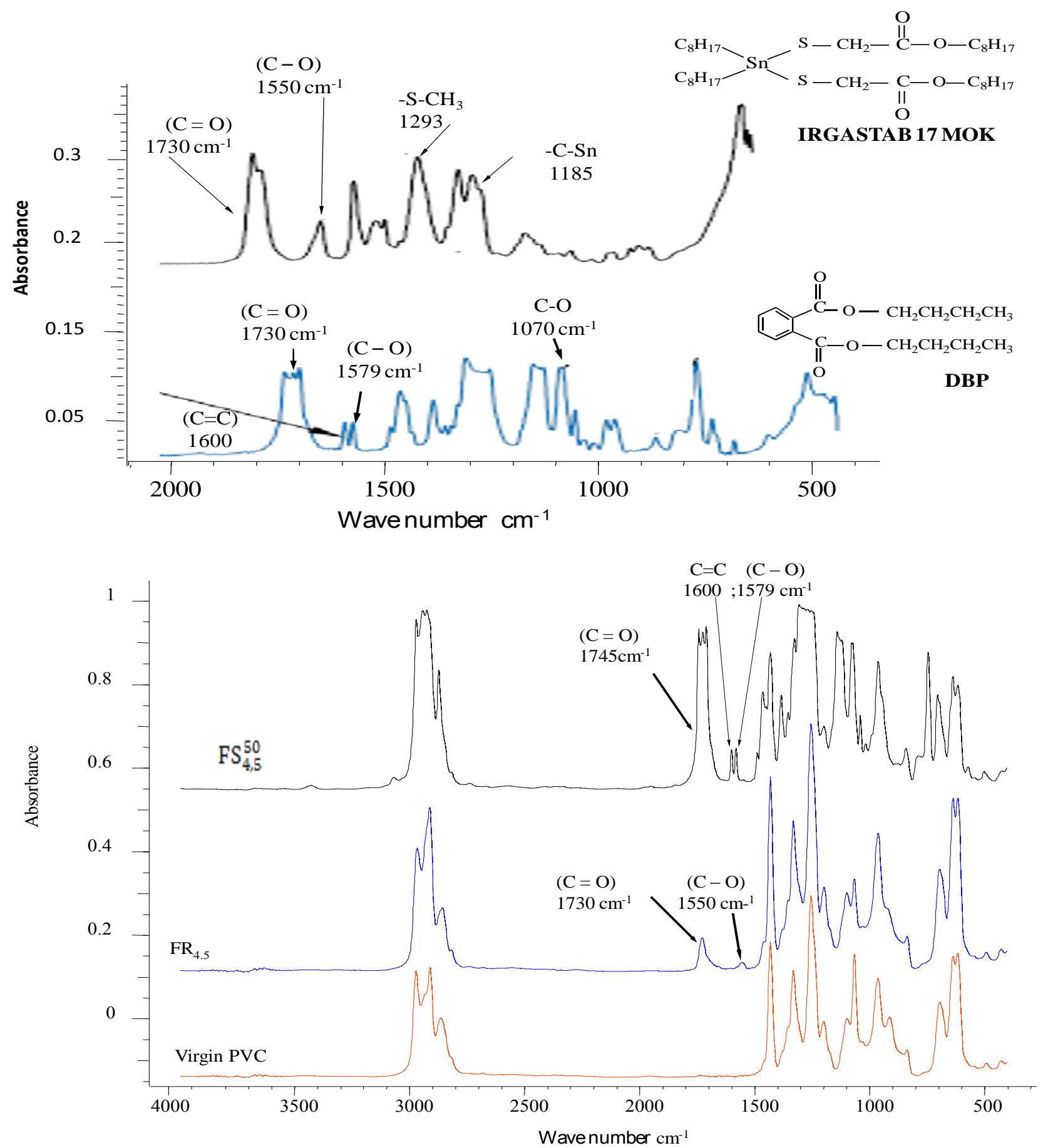

Figure 1. IRTF Spectrum rigid $\left(\mathrm{FR}_{4.5}\right)$ and plasticized $\quad$ PVC films. 
Then modification of common and specific absorption bands area of additives after migration testing can be correlated to a phenomenon of plasticizer migration. Therefore, DBP migration would be observed by the regression specific band at $1579 \mathrm{~cm}^{-1}$ (figure 2).

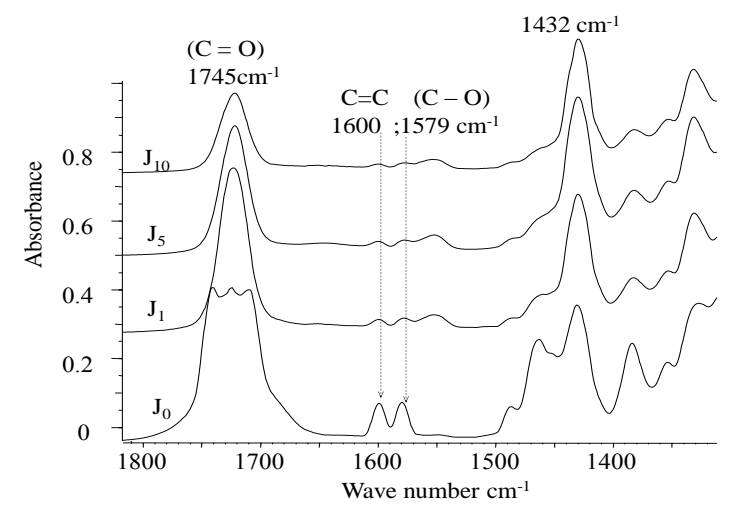

Figure 2. FTIR spectrum of plasticized PVC films in ethanol at $40^{\circ} \mathrm{C}$.

A quantitative estimation of this additive migration was carried out. For that purpose the area's ratios $A_{1579} / A_{1432}$ were calculated as a function of time. The band at 1432 $\mathrm{cm}^{-1}$ is due to the vibration of $\mathrm{CH}_{2}$ of $\mathrm{PVC}$ and was taken as a reference band [8]. On the other hand, the migration kinetic of DBP was followed in ethanol and hexane by observing the increase GC chromatographic peak at $2.34 \mathrm{mn}$. The obtained rates of migration $\left(M_{t} / M_{0}\right)$ are given in Figure 3, where $M_{t}$ and $M_{0}$ were migrated and initial DBP amounts, respectively.

It can be observed that the additive migration is related to the temperature. As it is mentioned in the literature, the migration is more important at higher temperatures [11-14]. It is obvious that the mobility of the migrant molecules increases with enhancement temperature, since the highest migration is obtained at $70{ }^{\circ} \mathrm{C}$.

Indeed, in ethanol the gas chromatography and IRTF spectroscopy show that DBP migration exceeds $80 \%$. At $40^{\circ} \mathrm{C}$, with the same analytical techniques, the results show that only $33.29 \%$ and $60.85 \%$ of DBP were lost, respectively.

To observe the effect of the liquid composition on the DBP diffusion from plasticized films migration tests were carried out in hexane and ethanol for 10 days at $40{ }^{\circ} \mathrm{C}$. Figure 4 shows that DBP migration rates detected by GC in ethanol and hexane are quite similar.

However, by FTIR we observe that DBP migration is more important in ethanol than hexane. It seems the ethanol and hexane penetrated the PVC films. The sorption of volatile solvents by polymeric films was already mentioned in literature $[9,10]$. The presence of ethanol in the films could be observed by FTIR the development of the $\mathrm{OH}$ band in the films spectrum after migration tests at 40 or $70{ }^{\circ} \mathrm{C}$ (figure 5), so it is easy to control the desorption of ethanol by films drying.

With hexane, it is difficult to distinguish its characteristic bands since they overlap with PVC.
Therefore, the real migration of DBP would be hidden in hexane.

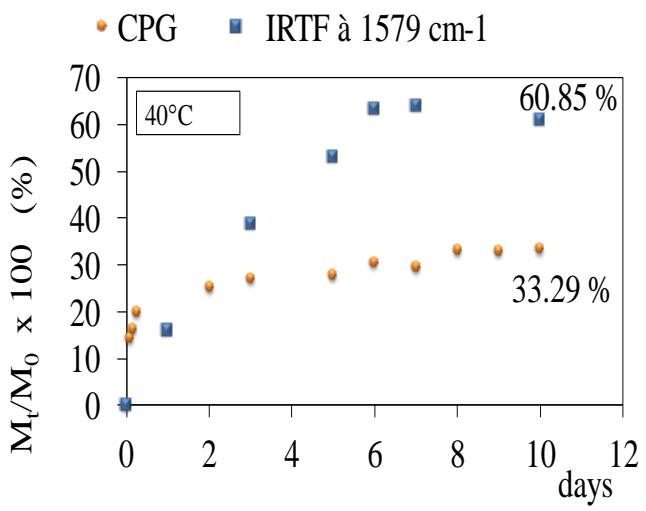

\section{- CPG IRTF à $1579 \mathrm{~cm}-1$}

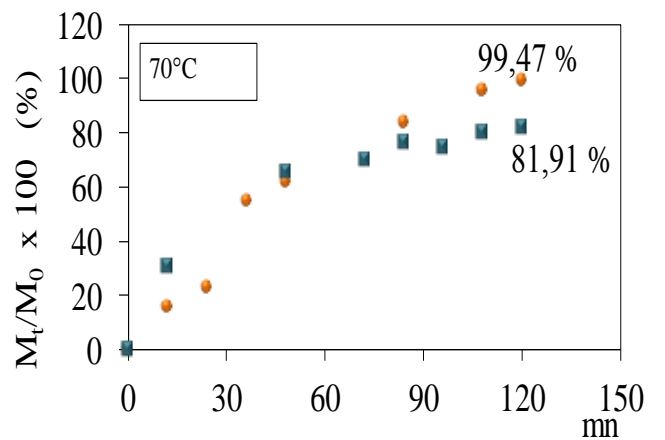

Figure 3. Migration kinetic of DBP in ethanol with

for 2 hours at $70^{\circ} \mathrm{C}$ and 10 days at $40^{\circ} \mathrm{C}$.
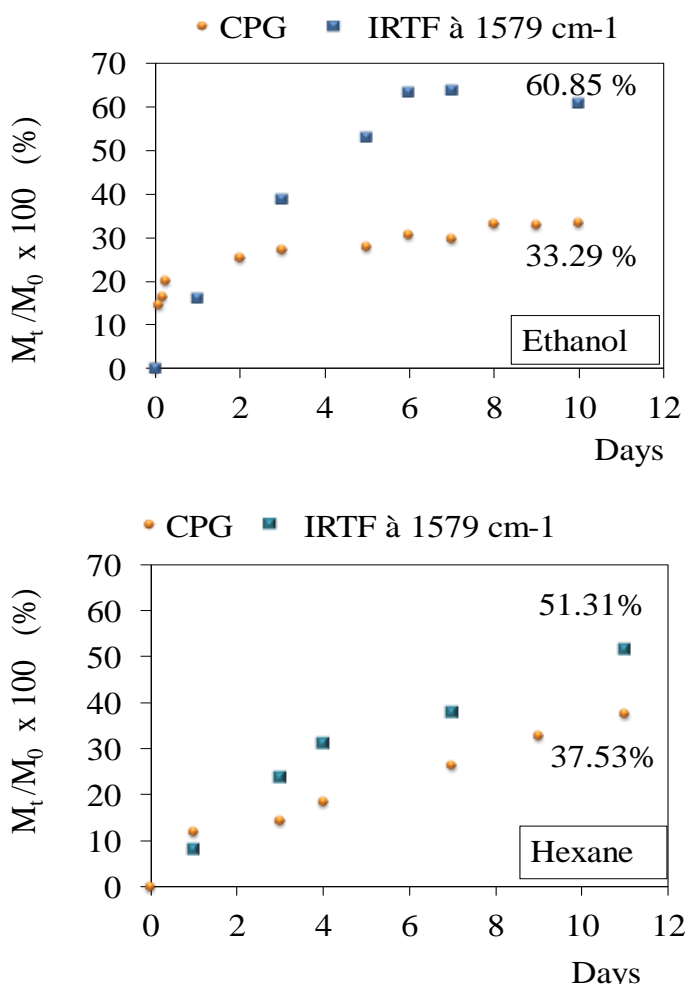

Figure 4. Migration kinetic of DBP in ethanol and hexane with for 10 days at $40^{\circ} \mathrm{C}$. 


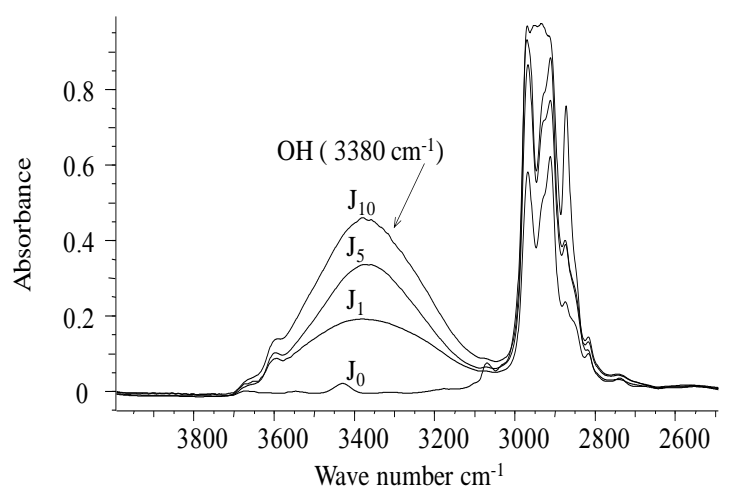

Figure 5. FTIR spectrum of in ethanol for 10 days at $40^{\circ} \mathrm{C}$

\subsection{IRGASTAB 17 MOK migration: UV-Visible at $490 \mathrm{~nm}$ investigation}

The specific migration of heat stabilizer IRGASTAB 17 MOK was carried out in hexane at $40{ }^{\circ} \mathrm{C}$ with the plasticized films and rigid $\mathrm{FR}_{\mathrm{x}}(\mathrm{x}: 0.75 ; 1.5 ; 2.5$; 3.5 and 4.5). As shown in Figure 6 migration rates (\%) obtained increase with IRGASTAB 17 MOK concentration in rigid and plasticized films according to literature data $[9,11-14]$.
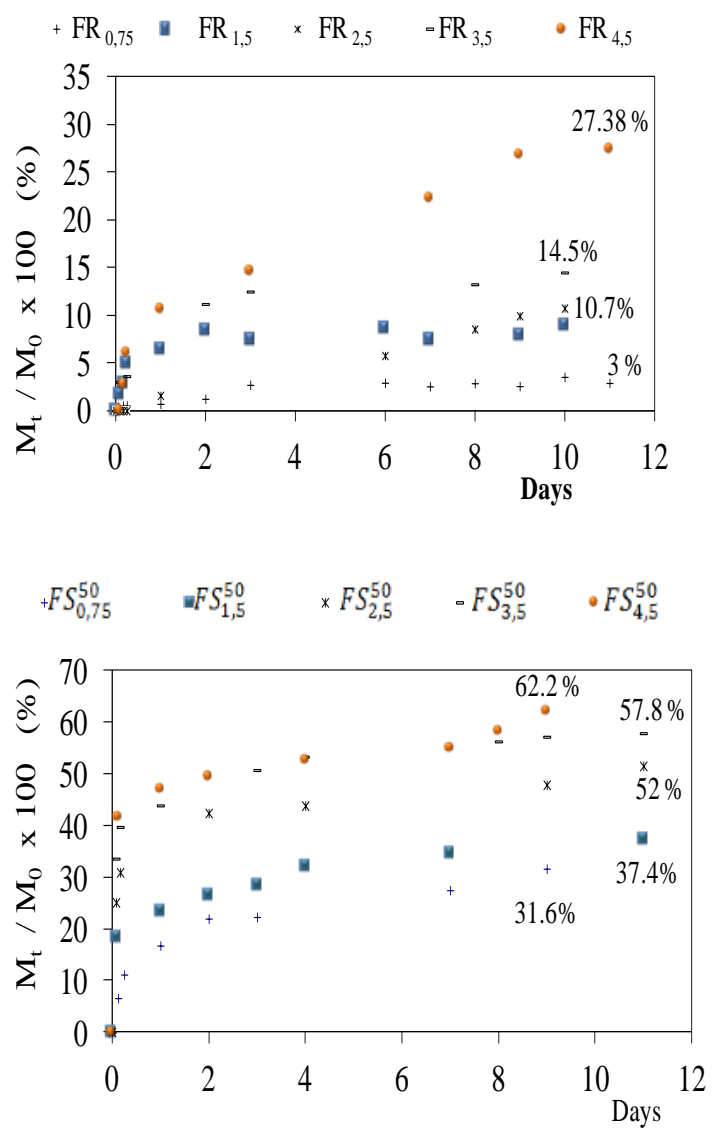

Figure 6. Migration kinetic of IRGASTAB 17MOK in hexane with $\mathrm{FR}_{\mathrm{x}}$ rigid and plasticized at $40^{\circ} \mathrm{C}$.

The presence of the plasticizer in films accelerates heat stabilizer migration $[9,11,12,14]$, obtained rates migration were 2.25 times higher than rigid films $\mathrm{FR}_{4.5}$.
For heat stabilizer concentrations between (x: $1.5 ; 2.5$ and $3.5 \%$ ), plasticized films rates diffusion were 4 times greater than rigid films $\mathrm{FR}_{\mathrm{x}}$.

\section{Conclusion}

The study of DBP migration was carried by GC and FTIR spectroscopy in ethanol and hexane at $40{ }^{\circ} \mathrm{C}$ and $70{ }^{\circ} \mathrm{C}$ with . Rates migration obtained at $70{ }^{\circ} \mathrm{C}$ are higher than $40^{\circ} \mathrm{C}$ in ethanol. IRTF spectroscopy could substitute gas chromatography. The results obtained by gas chromatography are quite similar. In hexane and ethanol at $40{ }^{\circ} \mathrm{C}$ and they are lower than FTIR spectroscopy. Increasing temperature, heat stabilizer concentration and the presence of the plasticizer in the films accelerate migration.

Gas chromatography could be substituted by FTIR spectroscopy to investigate the DBP migration phenomena. It is a simple, low cost and rapid method which can be used.

\section{References}

1. R.J. Crawford, Plastics Engineering, Press, $2^{\text {nd }}$ ed., Pergamon, Belfast, 1987

2. J. Bost, Matières Plastiques, Chimie- Applications, Tech\&Doc-Lavoisier, 1985

3. M. Bisson, J.G Bureau, G.;Gay, S. Joachim, G. La Croix, J.P. Lefevre, M.P Strub, S. Tissot, INERISFiche de données toxicologiques et environnementales des substances chimiques, oxyde de tributyle étain 2005, Version $\mathrm{N}^{\circ} 2-1$

4. S. Hill, B. Shaw and Clin, A.Wu. Chim. Acta 3041 (2001)

5. N.H. Stoffers, R. Brandsch, E. L. Bradley, I. Cooper, M. Dekker, A. Störmer, R. Franz, Food Additives and Contaminants 22173 (2005)

6. V. Alexeev, Analyse qualitative, MIR, Moscou, 1980

7. G. Charlot, Dosages absorptiométriques des éléments minéraux, Masson, Paris, 1978

8. G. Socrates, Infrared characteristic group frequencies, Wiley publication, New York, 1980

9. M. Vergnaud, Liquid transport processes in polymeric materials, Modeling and Industrial applications, Prentice Hall, Englewood Cliffs, New Jersey, 1992

10.C. Sammon, J. Yarwood, N. Everall, Polymer 41 2521 (2000)

11.C. Zeddam and N. Belhaneche-Bensemra, J. Polymeric Materials 59318 (2010)

12. N. Belhaneche-Bensemra, C. Zeddam, S Ouahmed, Macromol. Symp. 180 (2002)

13.A. Feigenbaum, Evaluation de la migration des matériaux plastiques au contact des aliments par des méthodes alternatives, L'emballage des denrées alimentaires de grandes consommations, Technique \& Documentation Lavoisier, Paris, 1998

14.M.O. Boussoum, D. Atek, N. BelhanecheBensemra, Polym. Degrad. Stab 579 (2006) 